\title{
Copolymer SJ-1 as a Fluid Loss Additive for Drilling Fluid with High Content of Salt and Calcium
}

\author{
Hongping Quan,, ${ }^{1,2}$ Huan Li, ${ }^{1,2}$ Zhiyu Huang, ${ }^{1,2}$ Tailiang Zhang, ${ }^{1,2}$ and Shanshan Dai ${ }^{1,2}$ \\ ${ }^{1}$ School of Chemistry and Chemical Engineering, Southwest Petroleum University, Chengdu 610500, China \\ ${ }^{2}$ Department of Education, Engineering Research Center of Oilfield Chemistry, Chengdu 610500, China \\ Correspondence should be addressed to Shanshan Dai; 31617468@qq.com
}

Received 4 May 2014; Revised 11 July 2014; Accepted 26 July 2014; Published 18 August 2014

Academic Editor: Saad Khan

Copyright (c) 2014 Hongping Quan et al. This is an open access article distributed under the Creative Commons Attribution License, which permits unrestricted use, distribution, and reproduction in any medium, provided the original work is properly cited.

\begin{abstract}
A ternary copolymer of 2-acrylamide-2-methyl propane sulfonic acid (AMPS), acrylamide (AM), and allyl alcohol polyoxyethylene ether (APEG) with a side chain polyoxyethylene ether $\left(\mathrm{C}_{2} \mathrm{H}_{4} \mathrm{O}\right)_{n} \mathrm{SJ}-1$ were designed and synthesized in this work. Good temperature resistance and salt tolerance of "- $\mathrm{SO}_{3}{ }^{-}$" of AMPS, strong absorption ability of "amino-group" of AM, and good hydrability of side chain polyoxyethylene ether $\left(\mathrm{C}_{2} \mathrm{H}_{4} \mathrm{O}\right)_{n}$ of APEG provide $\mathrm{SJ}$-1 excellent properties as a fluid loss additive. The chemical structure of ternary copolymer was characterized by Fourier transform infrared (FTIR) spectroscopy. The molecular weight and its distribution were determined by gel permeation chromatography (GPC). The API fluid loss of drilling fluid decreased gradually with the increasing concentration of $\mathrm{NaCl}$ and $\mathrm{CaCl}_{2}$ in the mud system. SJ-1 was applied well in the drilling fluid even at a high temperature of $220^{\circ} \mathrm{C}$. Results of zeta potential of modified drilling fluid showed the dispersion stability of drilling fluid system. Scanning electron microscopy (SEM) analysis showed the microstructure of the surface of the filter cake obtained from the drilling fluid modified by SJ-1.
\end{abstract}

\section{Introduction}

Water-based drilling muds including bentonite were wellknown and widely used in the petroleum industry recently [1-4]. The main components of water-based drilling fluid are water, salt, insert solids, and clays such as montmorillonite. Among the important functions of water-based drilling fluid were to form filter cake on the wall of the well bore, prevent water leakage, and maintain the stability of the well wall [5]. The properties of the water-based drilling fluid, such as the rheology and filtration loss, are affected by the fluid loss additive. Polymers, which are nontoxic, degradable, and environment friendly [6-8], are the best choice to be used as drilling fluids additives. However, the traditional polymers as fluid loss additive are not stable at the work condition of drilling fluid, especially at high salt condition and high temperatures. The resulting drilling fluids often present poor properties such as high filtration. If the drilling fluid was applied in the high salt or calcium environment, the flocculated structure of clay particles will appear and the value of API fluid loss will increase obviously. Furthermore downhole accident such as borehole collapse will happen in severe case. To solve the problems mentioned above, a novel fluid loss additive SJ-1 was developed in this work [2, 9-11].

To make sure the fluid loss additive has an excellent ability of absorption, the monomer with strong absorption groups, such as amino-group, are introduced $[12,13]$. To make sure the additive has an excellent ability of salt tolerance, the monomers with stable group which is not sensitive to the cation, such as $-\mathrm{SO}_{3}{ }^{-}$, are introduced [14-16]. To make the fluid loss additive have an excellent ability of temperature resistance, the monomers with inflexibility groups such as big side group are introduced. At the same time, the monomers that are hard to hydrolyze are introduced to get rid of the side effect hydrolysis, such as polyoxyethylene ether $\left(\mathrm{C}_{2} \mathrm{H}_{4} \mathrm{O}\right)_{n}$ [17]. In this work, a good property of filtrate loss control even at high temperatures and salt condition of SJ-1 is synthesized by polymerization of AMPS, AM, and APEG. 


\section{Experimental}

2.1. Materials. AMPS and AM were from Chengdu Kelong Chemical Reagent Factory (China). APEG-1000 were of industrial grade from Jiangsu Haian petrochemical factory (China). Potassium persulfate, sodium hydroxide, and sodium bisulfite were analytical grade from Chengdu Kelong Chemical Reagent Factory (China).

2.2. Synthesis. APEG $(0.006 \mathrm{~mol})$ was added in a threenecked flask, using moderate amount of water to dissolve in a heated water bath. And then AMPS $(0.029 \mathrm{~mol})$ and $\mathrm{AM}(0.084 \mathrm{~mol})$ were added to the mixed solution. The $\mathrm{pH}$ was adjusted to $7-8$ with $\mathrm{NaOH}$. Finally, $0.2 \mathrm{wt} \%$ potassium persulfate and sodium bisulfite were added into the system. The reaction was performed under $60^{\circ} \mathrm{C}$ with stir speed of $300 \mathrm{rmp}$. After completion of the reaction, the product was extracted with ethanol, shear granulation, vacuum drying, and grinding to obtain a white powdery polymer fluid loss additive. Chemical structure of SJ-1 was shown in Scheme 1.

In laboratory studies, the best parameters of copolymer SJ-1 were obtained: monomer concentration was $15 \mathrm{wt} \%$; molar ratio of $n(\mathrm{AM}): n(\mathrm{AMPS}): n(\mathrm{APEG})$ was $14: 5: 1$; the reaction temperature was $60^{\circ} \mathrm{C}$; the concentration of monomer initiator was $0.2 \mathrm{wt} \%$.

2.3. Characterization. The pellet samples were prepared by pressing the mixture of the SJ-1 and $\mathrm{KBr}$ and then measured with FTIR (WQF-520, China) spectrophotometer at range between 4000 and $500 \mathrm{~cm}^{-1}$.

The molecular weight distribution of SJ-1 was measured by GPC (Waters e2695, USA). The polymer was dissolved into distilled water forming the solution with concentration of $2 \mathrm{mg} / \mathrm{mL}$. The measurement was performed at the room temperature $\left(23^{\circ} \mathrm{C}\right)$ for $90 \mathrm{~min}$.

2.4. Sample Preparation. Freshwater base mud containing $4 \mathrm{wt} \%$ of sodium bentonite and $0.2 \mathrm{wt} \%$ of $\mathrm{Na}_{2} \mathrm{CO}_{3}$ was prepared by mixing the raw bentonite, $\mathrm{Na}_{2} \mathrm{CO}_{3}$, and freshwater at a certain ratio, stirring for $20 \mathrm{~min}$ at a high speed of $10000 \mathrm{rpm}$, and aging for $24 \mathrm{~h}$ at room temperature. Saltwater base mud was prepared by adding different concentration of $\mathrm{NaCl}$ into the above freshwater base mud and then submitted to a prehydration period of $24 \mathrm{~h}$. Calcium-water base mud was prepared by adding different concentration of $\mathrm{CaCl}_{2}$ into the above freshwater base mud and then submitted to a prehydration period of $24 \mathrm{~h}$. Polymer based mud was prepared by adding different concentration of SJ-1 into the freshwater base mud, salt-water base mud, and calcium-water base mud, respectively, and then submitted to a prehydration period of $24 \mathrm{~h}$.

2.5. Fluid Filtration Property Test. Drilling fluid filtrations were measured according to American Petroleum Institute (API) specifications and Chinese SY/T5621-93. The API filtrate volume (FLAPI) of the mud was determined with a medium-pressure filtration apparatus (ZNS-2 type, China).

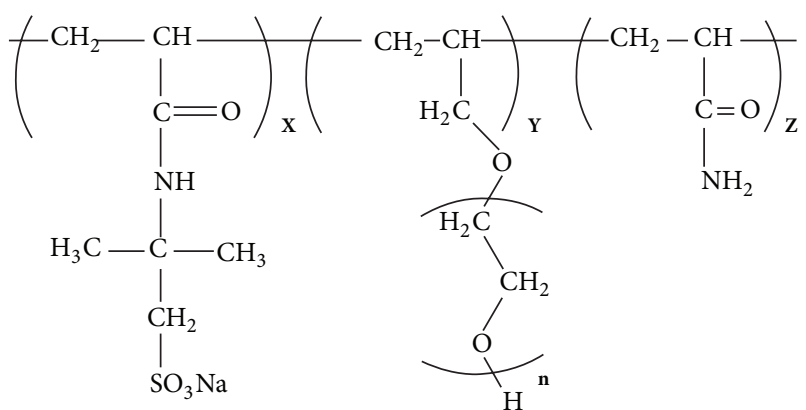

Scheme 1: Chemical structure of SJ-1.

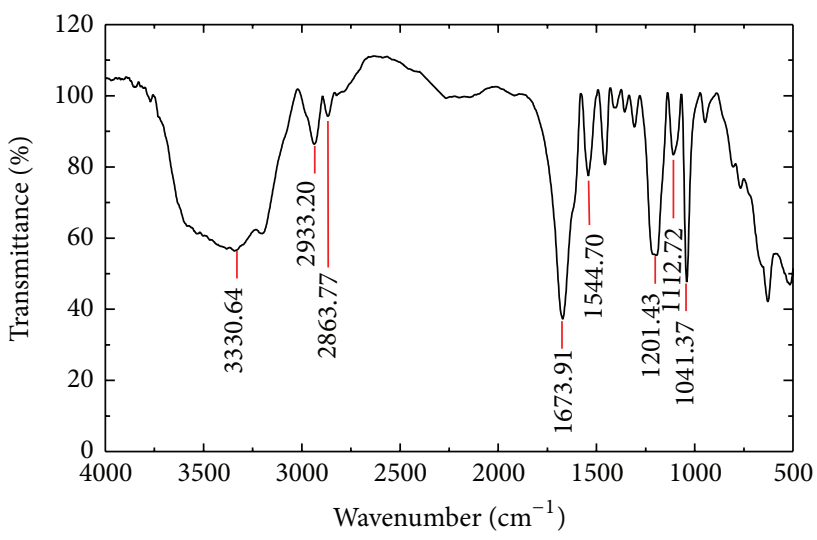

FIGURE 1: FTIR spectrum of polymerization product.

Apparent viscosity (AV), plastic viscosity (PV), and yield point (YP) were measured by rotational viscometer (ZNND6, China) at different temperatures.

Aging experiments of bentonite-polymer fluids were carried out in a frequency conversion rolling oven (BRGL-7 type, China) at a series of temperatures for $16 \mathrm{~h}$.

The filter cake of the sample was tested by SEM (JSM7500F, Japan) analysis and the filtrate of the sample was tested by zeta electric potential (Zeta PALS/90plus, Brookhaven, America) at different conditions.

\section{Results and Discussion}

3.1. Chemical Structure and Molecular Weight. The chemical structure of SJ-1 was analyzed by FTIR after being purified; the results were shown in Figure 1.

A strong absorption peak of $3330.64 \mathrm{~cm}^{-1}$ was assigned to the stretching vibration of $\mathrm{N}-\mathrm{H}$. The absorption peaks observed at $2933.20 \mathrm{~cm}^{-1}$ and $2863.77 \mathrm{~cm}^{-1}$ were due to the stretching vibration of $-\mathrm{CH}_{3}$ and $-\mathrm{CH}_{2}$, respectively. The absorption peak of $1673.91 \mathrm{~cm}^{-1}$ was attributed to the stretching peak of $\mathrm{C}=\mathrm{O}$. The absorption peak of $1544.70 \mathrm{~cm}^{-1}$ was due to the stretching vibration of $\mathrm{C}-\mathrm{N}$, while $1201.43 \mathrm{~cm}^{-1}$ was attributed to $\mathrm{C}-\mathrm{O}-\mathrm{C}$. Moreover, absorption peaks of $1112.72 \mathrm{~cm}^{-1}$ and $1041.37 \mathrm{~cm}^{-1}$ were according to the bending vibration of $-\mathrm{SO}_{3}{ }^{-}$. Results mentioned above were consistent with the chemical structure of SJ-1 shown in Scheme 1. 
TABLE 1: Relationship between SJ-1 concentration and fluid loss.

\begin{tabular}{lcccc}
\hline $\begin{array}{l}\text { SJ-1 concentration } \\
\text { /wt\% }\end{array}$ & $\begin{array}{c}\mathrm{AV} \\
\text { /mPa·s }\end{array}$ & $\begin{array}{c}\mathrm{PV} \\
/ \mathrm{mPa} \cdot \mathrm{s}\end{array}$ & $\begin{array}{c}\mathrm{YP} \\
\text { /Pa }\end{array}$ & $\begin{array}{c}\text { API filter loss } \\
/ \mathrm{mL}\end{array}$ \\
\hline 0.0 & 12.5 & 7.0 & 5.62 & 23.0 \\
0.1 & 16.0 & 10.0 & 6.13 & 11.8 \\
0.3 & 19.5 & 13.0 & 6.64 & 11.2 \\
0.6 & 23.5 & 16.0 & 7.67 & 10.4 \\
0.9 & 30.0 & 21.0 & 9.20 & 9.4 \\
1.2 & 37.0 & 26.0 & 11.24 & 9.2 \\
1.5 & 44.0 & 31.0 & 13.29 & 9.2 \\
1.8 & 52.5 & 36.0 & 16.86 & 9.1 \\
\hline
\end{tabular}

The molecular weight and its distribution of SJ-1 which was synthesized under the best optimum synthesis condition mentioned in Section 2.2 were determined by GPC. The result showed that the weight average molecular weight was $8.1 \times$ $10^{5}$, and the number average molecular was $6.2 \times 10^{5}$. Thus, the molecular weight distribution coefficient is 1.29 . These all meet the technical requirements for oilfield application [18].

\subsection{Effect of Concentration of SJ-1 on the Properties of Drilling} Fluid. Different concentration of SJ-1 was added to the freshwater base mud. The rheological and API fluid loss properties have been measured by rotational viscometer and mediumpressure filtration apparatus, respectively. The results were shown in Table 1.

According to Table 1, with the increase of loading of SJ1, the API fluid loss of drilling fluid decreased obviously. The values of fluid loss became stable, when the concentrations of SJ-1 was no less than $1.2 \mathrm{wt} \%$. At the same time, the rheological property of drilling fluid changed as the increase of polymer concentration. SJ-1 contributes to build up the network structure, which results in a viscosity-building ability. If the rheological property of drilling fluid was bad, thinner might be required for the drilling fluid, so the optimum concentration of fluid loss addictive SJ-1 in the freshwater base mud was $1.2 \mathrm{wt} \%$.

3.3. Evaluation of Temperature Resistance. $1.2 \mathrm{wt} \% \mathrm{SJ}-1$ was added to the freshwater base mud, then, rolling in frequency conversion rolling oven for $16 \mathrm{~h}$ at different levels of temperature. The rheological and API fluid loss have been measured by rotational viscometer and medium-pressure filtration apparatus, respectively. The results were shown in Table 2.

The value of API fluid loss of drilling fluid raised with the increase of temperature, when the concentration of SJ1 was equal to $1.2 \mathrm{wt} \%$. The API fluid loss of drilling fluid was still below $13 \mathrm{~mL}$ even at $220^{\circ} \mathrm{C}$ showing its property of temperature resistant. Three reasons account for this phenomenon. Firstly, the main chain of the polymeric molecule is connected by $\mathrm{C}-\mathrm{C}$, which is stable at high temperatures. Secondly, the $-\mathrm{SO}_{3}{ }^{-}$of the AMPS has a strong temperature resistance performance, introducing the $-\mathrm{SO}_{3}{ }^{-}$into the polymer molecule can significantly improve the property of
TABLE 2: Fluid loss of drilling fluid changed with aging temperature.

\begin{tabular}{lcccc}
\hline $\begin{array}{l}\text { Experimental } \\
\text { conditions }\end{array}$ & $\begin{array}{c}\mathrm{AV} \\
/ \mathrm{mPa} \cdot \mathrm{s}\end{array}$ & $\begin{array}{c}\mathrm{PV} \\
/ \mathrm{mPa} \cdot \mathrm{s}\end{array}$ & $\begin{array}{c}\text { YP } \\
/ \mathrm{Pa}\end{array}$ & $\begin{array}{c}\text { API filter loss } \\
/ \mathrm{mL}\end{array}$ \\
\hline $120^{\circ} \mathrm{C}, 16 \mathrm{~h}$ & 43.5 & 34.5 & 9.20 & 10.6 \\
$140^{\circ} \mathrm{C}, 16 \mathrm{~h}$ & 38.5 & 32.0 & 6.64 & 10.6 \\
$160^{\circ} \mathrm{C}, 16 \mathrm{~h}$ & 20.8 & 17.0 & 3.83 & 11.5 \\
$180^{\circ} \mathrm{C}, 16 \mathrm{~h}$ & 13.0 & 9.5 & 3.58 & 12.1 \\
$200^{\circ} \mathrm{C}, 16 \mathrm{~h}$ & 13.0 & 11.0 & 2.04 & 12.5 \\
$220^{\circ} \mathrm{C}, 16 \mathrm{~h}$ & 12.5 & 11.0 & 1.53 & 13.0 \\
\hline
\end{tabular}

TABLE 3: Performance evaluation of salt resistance of drilling fluid at high temperature.

\begin{tabular}{lccccc}
\hline $\begin{array}{l}\text { Experimental } \\
\text { conditions }\end{array}$ & $\begin{array}{c}\mathrm{NaCl} \\
\text { concentration } \\
/ \text { wt } \%\end{array}$ & $\begin{array}{c}\mathrm{AV} \\
/ \mathrm{mPa} \cdot \mathrm{s}\end{array}$ & $\begin{array}{c}\mathrm{PV} \\
/ \mathrm{mPa} \cdot \mathrm{s}\end{array}$ & $\begin{array}{c}\mathrm{YP} \\
/ \mathrm{Pa}\end{array}$ & $\begin{array}{c}\text { API filter } \\
\text { loss } \\
/ \mathrm{mL}\end{array}$ \\
\hline & 0.0 & 32.0 & 27.5 & 4.60 & 10.6 \\
& 2.0 & 20.0 & 17.5 & 2.56 & 16.0 \\
Aging & 5.0 & 17.5 & 15.0 & 2.56 & 13.0 \\
temperature & 10.0 & 18.0 & 16.0 & 2.04 & 12.6 \\
$120^{\circ} \mathrm{C}$, aging & 15.0 & 17.0 & 15.0 & 2.04 & 12.6 \\
time 16 h & 20.0 & 17.0 & 15.0 & 2.04 & 12.6 \\
& 25.0 & 17.5 & 15.0 & 2.56 & 10.4 \\
& 30.0 & 19.5 & 18.0 & 1.53 & 7.5 \\
\hline
\end{tabular}

temperature resistance. Lastly, APEG molecule contains a polyoxyethylene group, which can improve the hydrophilic property and the adsorption capacity of the SJ-1 at high temperatures.

With the increase of temperature, the rheological property of drilling fluid which reflected on apparent viscosity, plastic viscosity, and yield value decreased. Some of the SJ-1 was degraded at high temperature, which can lead to breaking up the network structure to a certain extent. But this negative influence held within limits and control. The little change on the performance of the drilling fluid was less affected.

\subsection{Evaluation of Salt Tolerance}

3.4.1. The Effect of $\mathrm{NaCl}$ at $120^{\circ} \mathrm{C}$. $1.2 \mathrm{wt} \% \mathrm{SJ}-1$ and different concentration of $\mathrm{NaCl}$ were added to the freshwater base mud and, then, aged $16 \mathrm{~h}$ at $120^{\circ} \mathrm{C}$. The rheological and API fluid loss have been measured by rotational viscometer and medium-pressure filtration apparatus, respectively. The results were shown in Table 3.

Table 3 illustrated that the API fluid loss of drilling fluid decreased gradually by the growing concentration of $\mathrm{NaCl}$ in the mud system. When the salt concentration was $30 \mathrm{wt} \%$, the fluid loss achieved the lowest level, namely $7.5 \mathrm{~mL}$, which indicated the good salt tolerance of SJ-1.

Five reasons account for this phenomenon. Firstly, when the $\mathrm{NaCl}$ was added to the freshwater base mud, the value of the zeta electric potential of the clay particles would decrease and the hydration shell would be reduced, which would lead to generating the flocculated structure in the freshwater base 
TABLE 4: Performance evaluation of calcium resistance of drilling fluid under high temperature.

\begin{tabular}{lccccc}
\hline $\begin{array}{l}\text { Experimental } \\
\text { conditions }\end{array}$ & $\begin{array}{c}\mathrm{CaCl}_{2} \\
\text { concentration } \\
/ \mathrm{wt} \%\end{array}$ & $\begin{array}{c}\mathrm{AV} \\
/ \mathrm{mPa} \cdot \mathrm{s}\end{array}$ & $\begin{array}{c}\mathrm{PV} \\
/ \mathrm{mPa} \cdot \mathrm{s}\end{array}$ & $\begin{array}{c}\mathrm{YP} \\
/ \mathrm{Pa}\end{array}$ & $\begin{array}{c}\text { API filter } \\
\text { loss } \\
/ \mathrm{mL}\end{array}$ \\
\hline Aging & 0.0 & 32.0 & 27.5 & 4.60 & 10.6 \\
temperature & 2.0 & 9.5 & 9.0 & 0.51 & 26.0 \\
$120^{\circ} \mathrm{C}$, aging & 6.0 & 10.0 & 9.0 & 1.02 & 19.0 \\
time 16 h & 6.0 & 9.0 & 8.0 & 1.02 & 17.0 \\
& 8.0 & 8.5 & 8.0 & 0.51 & 12.6 \\
& 10.0 & 8.5 & 8.0 & 0.51 & 12.0 \\
\hline
\end{tabular}

mud. So, the API filter loss increases. Secondly, when the $\mathrm{NaCl}$ was added to the freshwater base mud, the adsorption of the fluid loss additive on the surface of the clay particles would increase, which would lead to the increase of the zeta electric potential of the clay particles and the thickening of hydration shell. So, the API filter loss would decrease. When the concentration of the $\mathrm{NaCl}$ was $2 \mathrm{wt} \%$, the effect of the $\mathrm{NaCl}$ on the clay particles played a leading role, and the API filter loss was increased. Meanwhile, with the increase of the concentration of the $\mathrm{NaCl}$, the effect of the $\mathrm{NaCl}$ on the fluid loss additive was increased and the API filter loss was decreased. When the concentration of the $\mathrm{NaCl}$ was $25 \mathrm{wt} \%$, the effect of the $\mathrm{NaCl}$ on the fluid loss additive played a leading role, so the API filter loss was lower than that without the $\mathrm{NaCl}$. Thirdly, the SJ-1 with good temperature resistant remains at a comparatively high level. And it is beneficial for adsorbing clay particles and free water to form aggregate, which forms a thin and dense mud cake on the wall. The appearance of mud cake effectively reduces the filtrate loss. Lastly, because of the adding of fluid loss additive SJ-1, the hydrophilic radical of this treating chemical mainly includes sulfonic acid and polyoxyethylene side chain which enjoy a favorable hydrophilicity and good solubility in a saline environment. It can bring enough hydrated film to clay and ensure the drilling fluid system has good salt tolerance.

3.4.2. The Effect of $\mathrm{CaCl}_{2}$ at $120^{\circ} \mathrm{C} .1 .2 \mathrm{wt} \% \mathrm{SJ}-1$ and different concentration of $\mathrm{CaCl}_{2}$ were added to the freshwater base mud and, then, aged $16 \mathrm{~h}$ at $120^{\circ} \mathrm{C}$. The rheological and filtration properties have been measured by rotational viscometer and medium-pressure filtration apparatus, respectively. The results have been shown in Table 4.

Table 4 illustrated that the fluid loss of drilling fluid decreased gradually by the growing number of $\mathrm{CaCl}_{2}$ in the mud system. When the $\mathrm{CaCl}_{2}$ was $8 \mathrm{wt} \%$, the fluid loss was lower than $12.6 \mathrm{~mL}$, however the API fluid loss remain unchanged with the increase of $\mathrm{CaCl}_{2}$. When the $\mathrm{CaCl}_{2}$ was $10 \%$, the API fluid loss was $12.0 \mathrm{~mL}$.

Two reasons account for this phenomenon. Firstly, the $-\mathrm{SO}_{3}{ }^{-}$of the SJ-1 molecular chain has strong hydration capacity and the hydration of the clay particles can be thickened. Meanwhile, the $-\mathrm{SO}_{3}{ }^{-}$and the calcium do not cause the precipitation reaction in the drilling fluid containing calcium ions. So the SJ-1 can form a thick hydration shell on the

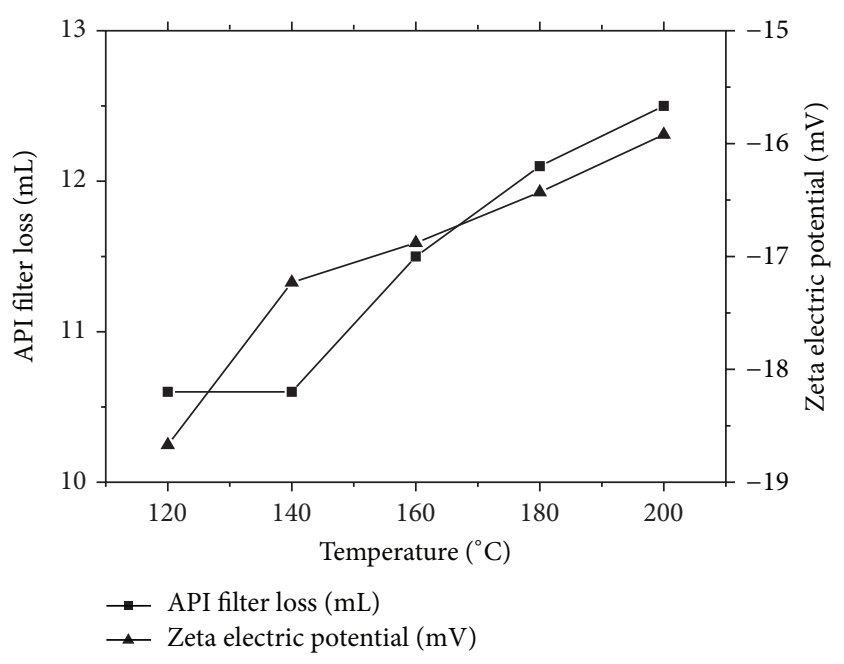

FIGURE 2: The impact of zeta electric potential and API filter loss on mud system in different temperatures.

surface of clay, which can ensure that the SJ-1 has good fluid loss performance in the drilling fluid containing calcium ions. Secondly, because of the $-\mathrm{SO}_{3}{ }^{-}$, the $\mathrm{SJ}-1$ can resist a temperature of $120^{\circ} \mathrm{C}$ in which polymer rarely degrades or degrades in a small quantity; the original nature of many polymer molecules can be maintained, and they can adsorb clay particles and free water, forming an aggregate that acts as a thin and dense mud cake on the borehole wall, which effectively reduces the leakage of filtrate into formation.

3.5. Zeta Electric Potential Test. $1.2 \mathrm{wt} \%$ SJ-1 was added to the freshwater base mud in different temperatures. The zeta electric potential and API filter loss have been measured by zeta potential analyzer and medium-pressure filtration apparatus, respectively. The results were shown in Figure 2.

Figure 2 shows that, in different temperatures, both drilling fluid system and zeta electric potential have a big change. The absolute value of the zeta electric potential of the mud system gradually decreased with the increase of aging temperature, and the filter loss gradually increases with the increase of experimental temperatures. It means that with the increase of aging temperatures, the character of mud system changes a lot, in which the absorption capacity of polymers on the surface of clay particles is reducing, leading to the increase of filter loss of mud. However, because the SJ-1 contains many $-\mathrm{SO}_{3}{ }^{-}$and side chain polyoxyethylene ether $\left(\mathrm{C}_{2} \mathrm{H}_{4} \mathrm{O}\right)_{n}$ which exhibits unique hydration and dispersion capacities at high temperature, the negative influence held within limits. The zeta electric potential test shows that this mud system still has a good dispersion stability in high temperature.

$1.2 \mathrm{wt} \% \mathrm{SJ}-1$ and different concentration of $\mathrm{NaCl}$ were added to the freshwater base mud at $25^{\circ} \mathrm{C}$. The zeta electric potential and API filter loss have been measured by zeta potential analyzer and medium-pressure filtration apparatus, respectively. The results were shown in Figure 3.

Figure 3 shows that, with an increase of $\mathrm{NaCl}$, filter loss is decreasing, along with the absolute value of zeta electric 


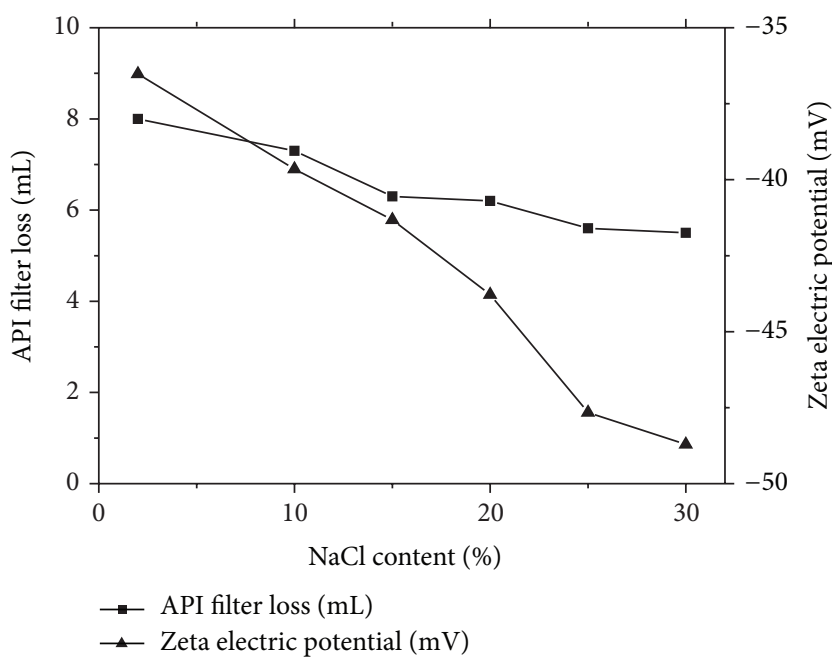

FIGURE 3: The impact of zeta electric potential and API filter loss on mud system in different salt contents.

potential rising up, which is compatible with the data of zeta electric potential test. With the increase of electrolyte, the coalescence of electrolyte is gradually gentle and the aggregation of clay particles in drilling fluid is impeded, resulting in the increase of the small particles in the mud with the expansion of the degree of mineralization. At the same time, SJ-1 particles are adsorbed on the surface of clay particles; sulfonic acid group can chemically react to $\mathrm{Na}^{+}$and $\mathrm{Ca}^{2+}$ in salt; the steric effect of polyoxyethylene side chain in particles is large. Thus, it is more difficult to aggregate clay particles, and the compression of salt on the electric double layer is reduced, with the improvement of the resistance of fluid loss additive to salt. In addition, with the increase of polymer, both apparent and plastic viscosities are increasing to a small extent.

3.6. SEM Analysis of Filter Cake. In order to explore the microstructure of the filter cake formation and the filtration mechanism research, the formation of the filter cake was observed by type JSM7500F SEM.

Freshwater base mud and polymers of $1.2 \mathrm{wt} \%$ density are added into drilling fluid to test the API filter loss in normal temperature. After drying, the appearance of filter cake can be seen through SEM in Figure 4.

Figure 4(a) shows that the surface of the base mud is uneven and friable, with some ravines and small poles. Some big particles can be seen, so the mud is bad in dispersion and the cake formed is of a poor quality, causing a terrible dehydration.

Figure 4(b) shows that after an aging process, the cakes are uniform and dense on their surfaces, with no big pores and coarse particles. Polymer adsorbed on clay particles, forming a reticulated polymer, which effectively blocks the pore of borehole wall and prevents the filtrate in the drilling fluid leaking to formation. Thus, the drilling fluid is presented to be in good character and the filtrate loss is less than base mud. Then, hydration swelling and dispersion of shale are

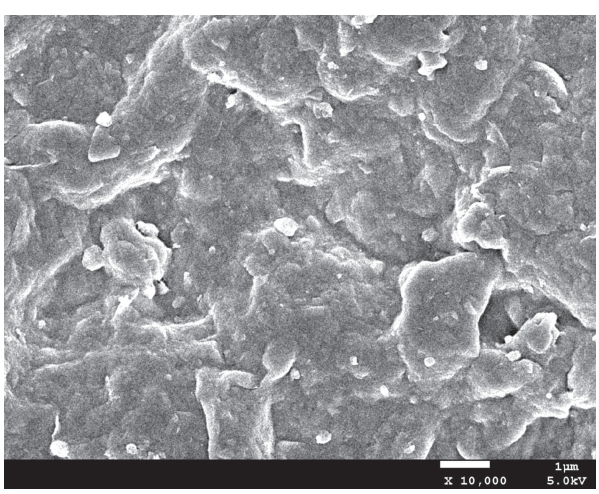

(a)

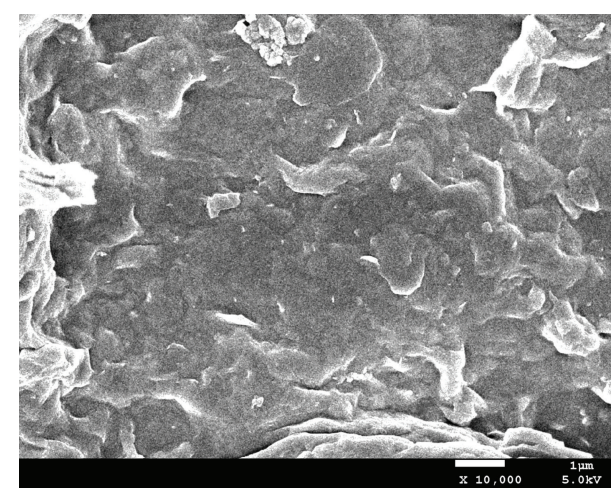

(b)

FIGURE 4: SEM photos of (a) API filter cake formed by base mud and (b) API filter cake modified with SJ-1 (both of aging temperature $\left.120^{\circ} \mathrm{C}\right)$.

decreasing, which can better avoid borehole wall collapsing to protect reservoir.

Freshwater base mud polymers of $1.2 \%$ density are added into freshwater base mud, which is then stirred up speedily for 10 minutes. Next, $\mathrm{NaCl}$ is mixed into it and then stirred up for 10 minutes. API filtrate loss is tested and Figure 5 shows the SEM images of the filter cake.

Figure 5(a) shows that the filter cakes, with $\mathrm{NaCl}$ of $30 \%$ density added into the mud system mixed with the fluid loss additive, are dense on their surfaces and distributed regularly in tight connection, narrowing the pores for less filtration loss. It means that filtration loss of drilling fluid can be effectively reduced by adding a large quantity of $\mathrm{NaCl}$ into drilling fluid system. The polyoxyethylene side chain in the fluid loss additive raises the resistance of polymers to salt, and its plastic-protection function impede the coalescence of $\mathrm{NaCl}$ to clay particles, contributing to the regular distribution of clay particles in the drilling fluid system. Thus, the cake formed is dense.

Figure 5(b) shows that the cakes, with $\mathrm{NaCl}$ of $30 \%$ density added into the mud system mixed with the fluid loss additive aging $30 \mathrm{~min}$ at $120^{\circ} \mathrm{C}$, are dense and smooth on their surfaces and are distributed regularly in tight connection, narrowing the pores of filtrate loss. 


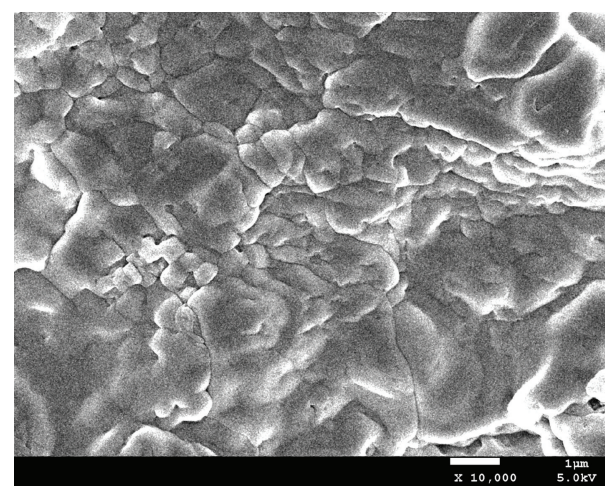

(a)

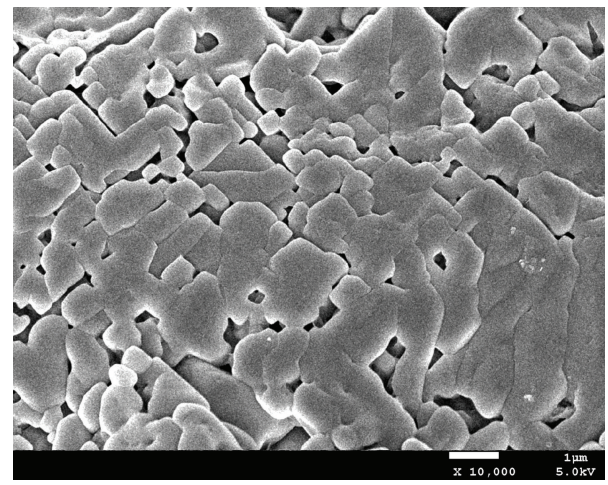

(b)

FIGURE 5: SEM photos of (a) API filter cake formed by base mud + SJ-1 + $30 \mathrm{wt} \% \mathrm{NaCl}$ and (b) API filter cake formed by base mud + $\mathrm{SJ}-1+30 \mathrm{wt} \% \mathrm{NaCl}$ after the aging process of $30 \mathrm{~min}$.

\section{Conclusions}

With FTIR analysis, the composition of the synthetic polymer SJ-1 was consistent to the designed structure. The weight average molecular weight of SJ-1 was $8.1 \times 10^{5}$, and its number average molecular was $6.2 \times 10^{5}$. The molecular weight distribution coefficient was 1.29 . The character evaluation proves that the best amount of SJ-1 in the mud is $1.2 \%$, and the API filtrate loss is $9.2 \mathrm{~mL}$. Salt resistance of SJ-1 is effective and keeps its effectiveness in the drilling fluid system in which the aging temperature is $220^{\circ} \mathrm{C}$, the mass density of $\mathrm{NaCl}$ is $30 \mathrm{wt} \%$, and $\mathrm{CaCl}_{2}$ is $10 \mathrm{wt} \%$. The zeta electric potential test on clay particles proves that with an increase of SJ-1, the API filtrate loss in drilling fluid is decreasing and the absolute value of zeta electric potential is increasing. Hydrated membrane is thickened by the increase of the density of negative charge of clay particles, contributing to the reduction of filtrate loss of drilling fluid. In addition, the SEM analysis proves that cakes with SJ-1 added in are even and dense on their surfaces with no big pores or coarse particles, and the filtrate loss is less than base mud. Besides, those cakes can effectively resist the pollution of electrolytes. And in the mud system with $\mathrm{NaCl}$ of $30 \%$ density, the cakes formed are distributed regularly in tight connection, narrowing the filtrate loss pores and reducing the amount of filtrate loss.

\section{Conflict of Interests}

The authors declare that there is no conflict of interests regarding the publication of this paper.

\section{Acknowledgment}

The authors thank the Engineering Research Center of Oilfield Chemistry, Ministry of Educational Key for experiment support.

\section{References}

[1] L. Ali and M. A. Barrufet, "Using centrifuge data to investigate the effects of polymer treatment on relative permeability," Journal of Petroleum Science and Engineering, vol. 29, no. 1, pp. $1-16,2001$.

[2] T. Wan, J. Yao, S. Zishun, W. Li, and W. Juan, "Solution and drilling fluid properties of water soluble AM-AA-SSS copolymers by inverse microemulsion," Journal of Petroleum Science and Engineering, vol. 78, no. 2, pp. 334-337, 2011.

[3] M. V. Kok, "Rheological and thermal analysis of bentonites for water base drilling fluids," Energy Sources A: Recovery, Utilization, and Environmental Effects, vol. 26, no. 2, pp. 145-151, 2004.

[4] M. V. Kok, "A rheological characterization and parametric analysis of a bentonite sample," Energy Sources A: Recovery, Utilization and Environmental Effects, vol. 33, no. 4, pp. 344348, 2011.

[5] Y. Zhuang, Z. Zhu, H. Chao, and B. Yang, "Effect of added salt on properties of aqueous SMP solution," Journal of Applied Polymer Science, vol. 55, no. 7, pp. 1063-1067, 1995.

[6] M. V. Kok, "Thermal characterization of sepiolite samples," Energy Sources A: Recovery, Utilization and Environmental Effects, vol. 35, no. 2, pp. 173-183, 2013.

[7] M. V. Kok, "Statistical approach of two-three parameters rheological models for polymer type drilling fluid analysis," Energy Sources A: Recovery, Utilization and Environmental Effects, vol. 32, no. 4, pp. 336-345, 2009.

[8] M. V. Kok, "Thermal analysis and rheological study of ocma type bentonite used in drilling fluids," Energy Sources A: Recovery, Utilization and Environmental Effects, vol. 35, no. 2, pp. 122-133, 2013.

[9] C. Collette, F. Lafuma, R. Audebert, and R. Brouard, "Macromolecular systems in heat-resistant drilling fluids; advantages of gels on linear polymers," Journal of Applied Polymer Science, vol. 53, no. 6, pp. 755-762, 1994.

[10] V. C. Kelessidis, C. Papanicolaou, and A. Foscolos, "Application of Greek lignite as an additive for controlling rheological and filtration properties of water-bentonite suspensions at high temperatures: a review," International Journal of Coal Geology, vol. 77, no. 3-4, pp. 394-400, 2009.

[11] R. Caenn and G. V. Chillingar, "Drilling fluids: state of the art," Journal of Petroleum Science and Engineering, vol. 14, no. 3-4, pp. 221-230, 1996.

[12] J. Plank, N. R. Lummer, and F. Dugonjić-Bilić, "Competitive adsorption between an AMPSV-based fluid loss polymer and Welan gum biopolymer in oil well cement," Journal of Applied Polymer Science, vol. 116, no. 5, pp. 2913-2919, 2010.

[13] J. Y. Ma, H. L. Zheng, M. Z. Tan et al., "Synthesis, characterization, and flocculation performance of anionic polyacrylamide $\mathrm{P}$ 
(AM-AA-AMPS)," Journal of Applied Polymer Science, vol. 129, no. 4, pp. 1984-1991, 2013.

[14] C. Tiemeyer and J. Plank, "Synthesis, characterization, and working mechanism of a synthetic high temperature $(200 \circ \mathrm{C})$ fluid loss polymer for oil well cementing containing allyloxy2-hydroxy propane sulfonic (AHPS) acid monomer," Journal of Applied Polymer Science, vol. 128, no. 1, pp. 851-860, 2013.

[15] Y. Liu, W. P. Gates, A. Bouazza, and R. K. Rowe, "Fluid loss as a quick method to evaluate hydraulic conductivity of geosynthetic clay liners under acidic conditions," Canadian Geotechnical Journal, vol. 51, no. 2, pp. 158-163, 2014.

[16] Q. Xiao, W. F. Xiao, and X. X. Liu, "A novel cement fluid loss additive P1402," Advanced Materials Research, vol. 941-944, pp. 1203-1207, 2014.

[17] S. Akimoto, S. Honda, and T. Yasukohchi, "Polyoxyalkylene alkenyl ether-maleic ester copolymer and use thereof," US Patent 5142036, 1989.

[18] J. P. Plank, "Water-based muds using synthetic polymers developed for high temperature drilling," Oil and Gas Journal, vol. 90, no. 9, pp. 40-45, 1992. 

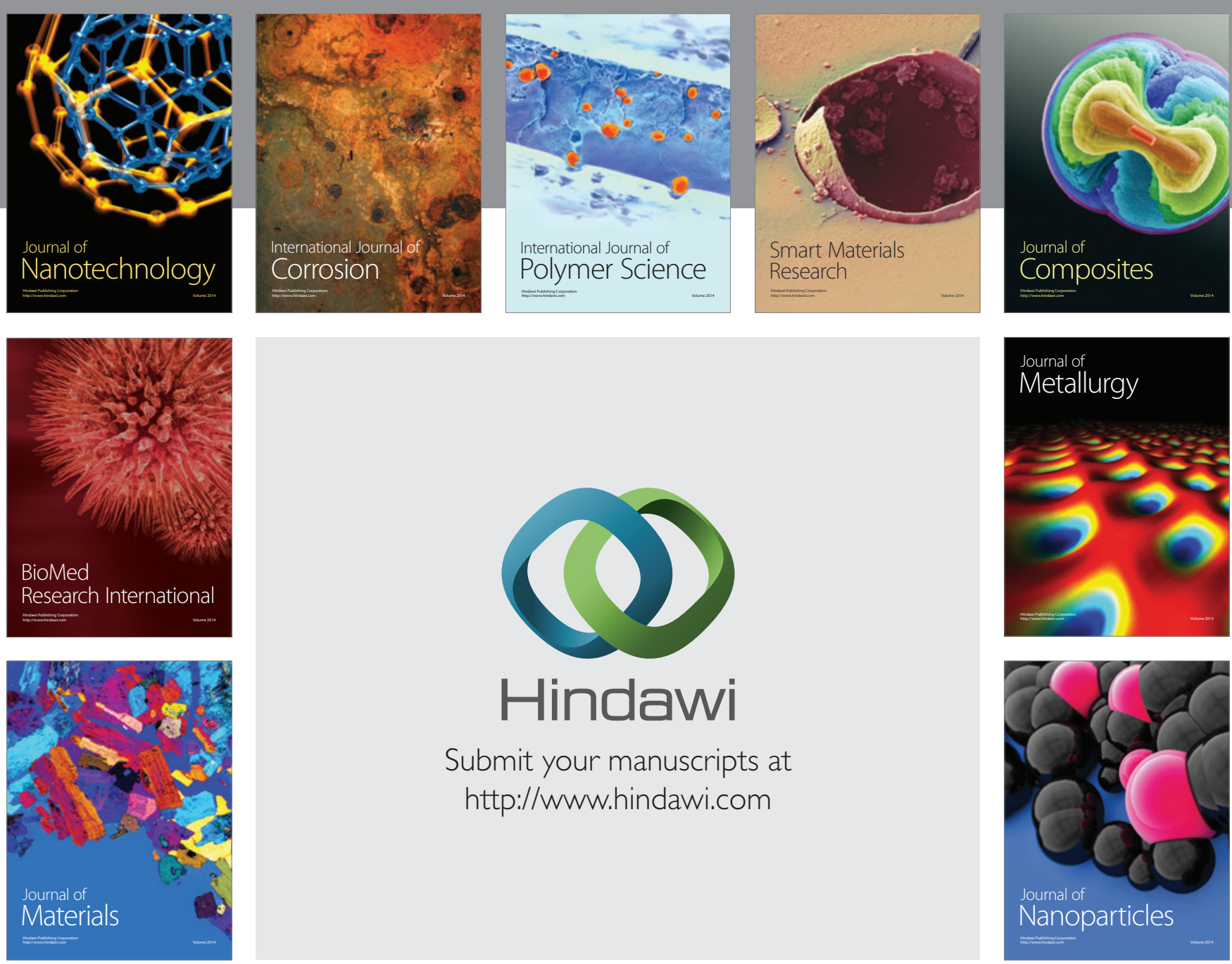

Submit your manuscripts at http://www.hindawi.com
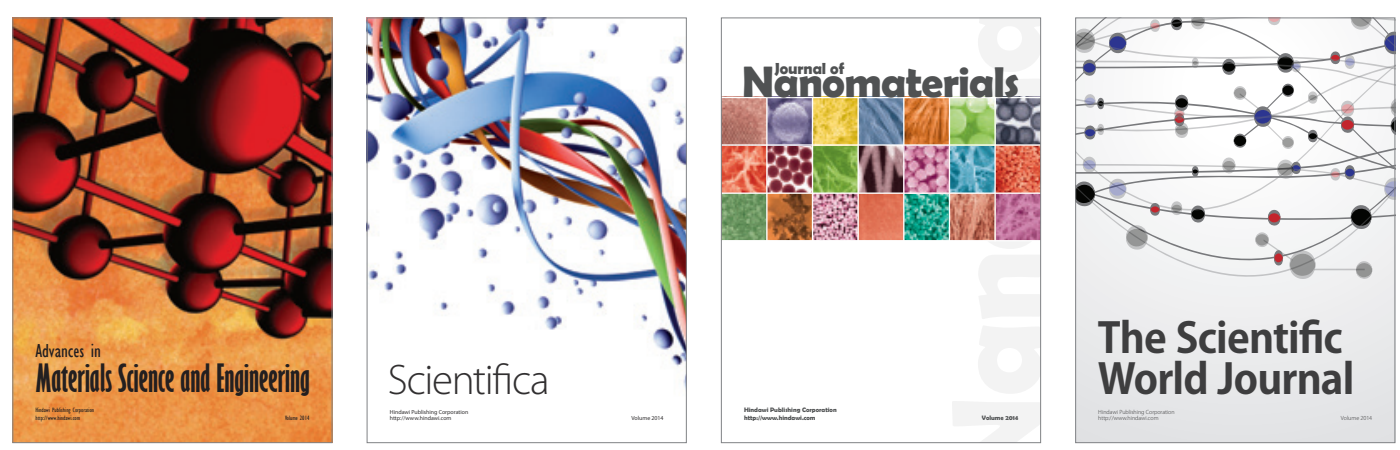

\section{The Scientific World Journal}
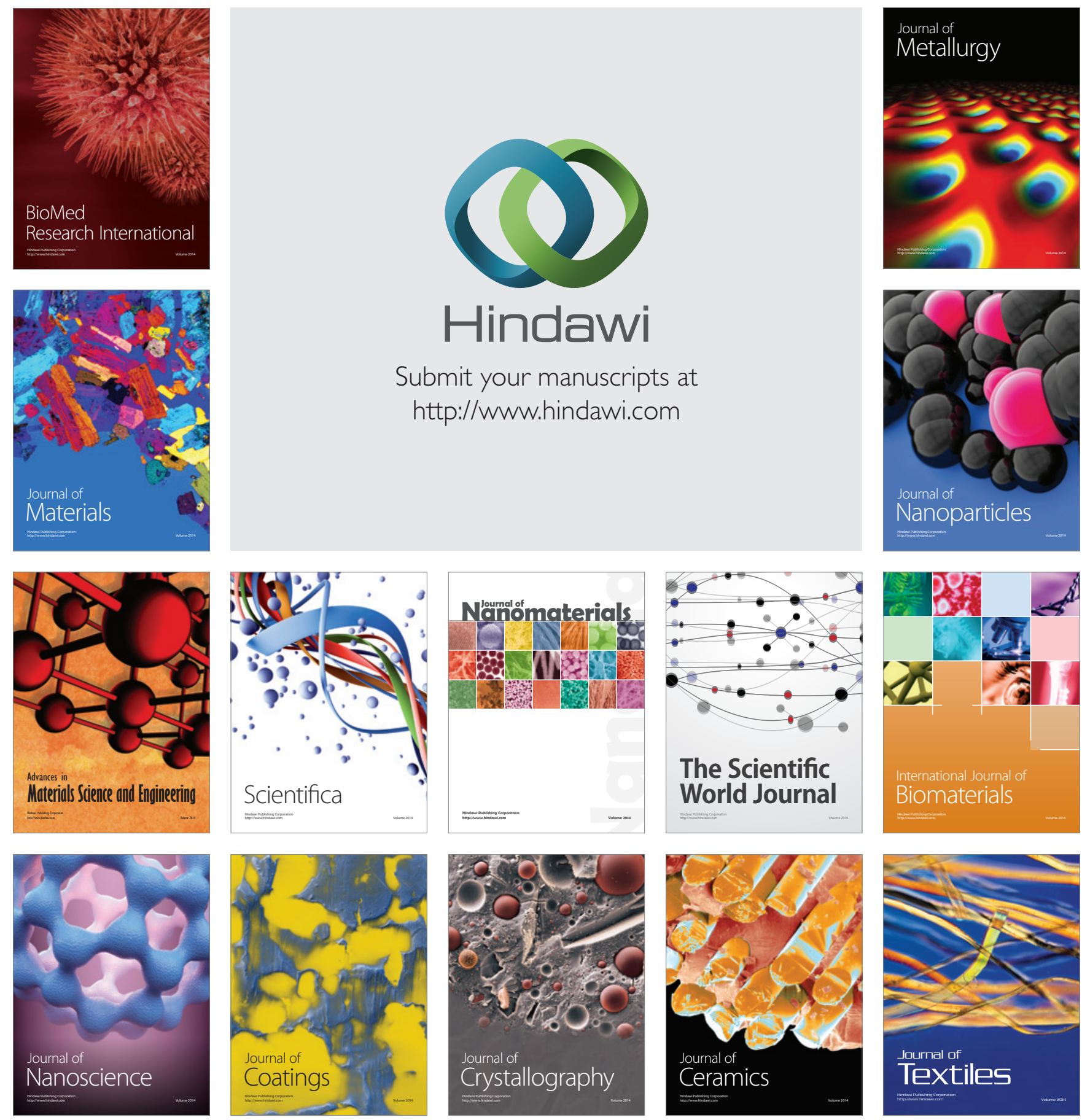